\title{
Changes in plasma levels of B-type natriuretic peptide with acute exacerbations of chronic obstructive pulmonary disease
}

This article was published in the following Dove Press journal:

International Journal of COPD

5 February 2014

Number of times this article has been viewed

\author{
Koichi Nishimura' \\ Takashi Nishimura ${ }^{2}$ \\ Katsuya Onishi ${ }^{3}$ \\ Toru Oga ${ }^{4}$ \\ Yoshinori Hasegawa ${ }^{5}$ \\ Paul W Jones ${ }^{6}$ \\ 'Department of Pulmonary Medicine, \\ National Center for Geriatrics and \\ Gerontology, Obu, Japan; ${ }^{2}$ Kyoto- \\ Katsura Hospital, Kyoto, Japan; ${ }^{3} \mathrm{Onishi}$ \\ Heart Clinic, Tsu, Japan; ${ }^{4}$ Department \\ of Respiratory Care and Sleep \\ Control Medicine, Graduate School \\ of Medicine, Kyoto University, Kyoto, \\ Japan; ${ }^{5}$ Division of Respiratory \\ Medicine, Department of Medicine, \\ Nagoya University Graduate School \\ of Medicine, Nagoya, Aichi, Japan; \\ ${ }^{6}$ Division of Clinical Science, St \\ George's Hospital Medical School, \\ London, England
}

Correspondence: Koichi Nishimura National Center for Geriatrics and Gerontology, Department of Pulmonary Medicine, 35 Gengo, Morioka, Obu, Aichi 474-85I I, Japan $\mathrm{Tel}+8 \mathrm{I} 56246231$ I

Fax +81562448518

Email koichi-nishimura@nifty.com
Background: Elevated plasma B-type natriuretic peptide (BNP) levels and their association with heart failure have been reported in subjects with acute exacerbations of chronic obstructive pulmonary disease (AECOPD).

Purpose: To examine and compare plasma BNP levels and diastolic and systolic dysfunction in subjects with AECOPD and stable chronic obstructive pulmonary disease (COPD).

Methods: In all, 87 unselected consecutive hospitalizations due to AECOPD in 61 subjects and a total of 190 consecutive subjects with stable COPD were recruited. Plasma BNP levels were compared cross-sectionally and longitudinally. Transthoracic echocardiographic examinations were also performed in the hospitalized subjects.

Results: In the hospitalized subjects, the median plasma BNP level (interquartile range) was 55.4 (26.9-129.3) pg/mL and was higher than that of patients with stable COPD: 18.3 (10.0-45.3) for Global Initiative for Chronic Obstructive Lung Disease grade I; 25.8 (11.0-53.7) for grade II; 22.1 (9.1-52.6) for grade III; and 17.2 (9.6-22.9) $\mathrm{pg} / \mathrm{mL}$ for grade IV, all $P<0.001$. In 15 subjects studied prospectively, the median plasma BNP level was $19.4(9.8-32.2) \mathrm{pg} / \mathrm{mL}$ before AECOPD, 72.7 (27.7-146.3) pg/mL during AECOPD, and 14.6 (12.9-39.0) pg/mL after AECOPD $(P<0.0033$ and $P<0.0013$, respectively). Median plasma BNP levels during AECOPD were significantly higher in ten unsuccessfully discharged subjects 260.5 (59.4-555.0) than in 48 successfully discharged subjects 48.5 (24.2-104.0) pg/mL $(P=0.0066)$. Only 5.6\% of AECOPD subjects were associated with systolic dysfunction defined as a left ventricular ejection fraction (LVEF) $<50 \%$; a further $7.4 \%$ were considered to have impaired relaxation defined as an E/A wave velocity ratio $<0.8$ and a deceleration time of $\mathrm{E}>240 \mathrm{~ms}$. BNP levels were weakly correlated with the E/peak early diastolic velocity of the mitral annulus (Ea) ratio (Spearman's rank correlation coefficient $=0.353, P=0.018$ ), but they were not correlated with the LVEF (Spearman's rank correlation coefficient $=-0.221, P=0.108$ ).

Conclusion: A modest elevation of plasma BNP is observed during AECOPD. It appears that AECOPD may have an impact on plasma BNP levels that is not attributable to heart failure.

Keywords: chronic obstructive pulmonary disease, acute exacerbations of chronic obstructive pulmonary disease, B-type natriuretic peptide, heart failure

\section{Introduction}

Acute exacerbation of chronic obstructive pulmonary disease (AECOPD) is a common cause of acute hospitalization ${ }^{1,2}$ and a great risk for morbidity and mortality. Since chronic obstructive pulmonary disease (COPD) is considered to be a systemic disorder, it has been reported that one of its multiple aspects is cardiovascular in nature. Although various cardiac diseases, including acute myocardial infarction ${ }^{3-5}$ and chronic heart failure (HF), ${ }^{6-17}$ may be associated with AECOPD, the typical 
presentation of a specific cardiac condition is rather exceptional in clinical practice.

The B-type natriuretic peptide (BNP) levels in the blood, which are used for the screening and diagnosis of acute decompensated $\mathrm{HF},{ }^{18,19}$ are also typically increased in patients with asymptomatic or symptomatic left ventricular dysfunction. It has also been reported that it is possible to recognize heart failure in elderly patients with stable COPD in primary care, ${ }^{20}$ and that BNP can be used to differentiate HF from respiratory diseases, including COPD, in patients with dyspnea, ${ }^{21-24}$ although there is no level of BNP that perfectly differentiates patients with and without HF. The Task Force for the Diagnosis and Treatment of Acute and Chronic Heart Failure 2008 of the European Society of Cardiology also reported that an evaluation of natriuretic peptide (BNP or N-terminal pro-brain natriuretic peptide [NT-proBNP]) levels may be helpful in this population, but the results are often preliminary. ${ }^{25}$

Bozkanat et al first reported that COPD patients had higher levels of BNP as compared to controls, and that BNP determination has a role in the diagnosis of cor pulmonale in patients with COPD. ${ }^{26}$ Abroug et al demonstrated that NT-proBNP is useful for excluding AECOPD associated with left ventricular dysfunction, since left-heart involvement in AECOPD was the only variable independently associated with the increased secretion of NT-proBNP. ${ }^{27}$ Inoue et al also reported elevated plasma BNP levels and a significant correlation with the percentage of ejection fraction and pulmonary artery systolic pressure in COPD. ${ }^{28}$ These authors appeared to consider that the high levels of BNP may be related to classical left ventricular dysfunction.

Abroug et al demonstrated that diastolic dysfunction was more frequent than systolic dysfunction in patients with AECOPD. ${ }^{27}$ Abusaid et al also reported that the diastolic dysfunction of the left ventricle in transthoracic echocardiography is common in subjects with AECOPD and may be associated with an increased frequency of hospitalization. ${ }^{29}$ On the other hand, Iwanaga et al reported that the plasma BNP levels reflect left ventricular end-diastolic wall stress more than any other parameter in systolic and diastolic HF, and that in a comparison between systolic and diastolic HF, the BNP level was significantly higher in systolic HF since the end-diastolic wall stress was also significantly higher in systolic than in diastolic HF. ${ }^{30}$ Therefore, we hypothesized that diastolic or systolic dysfunction could be detected using plasma BNP levels in subjects with AECOPD. The purpose of the present study was to evaluate diastolic and systolic dysfunction in subjects with AECOPD and stable COPD, mainly using the plasma levels of BNP.

\section{Methods}

\section{Subjects}

A total of 87 unselected consecutive hospitalizations due to AECOPD in 61 subjects were recruited from the Respiratory Division of the Kyoto-Katsura Hospital in Kyoto, Japan, a general hospital that provides health care mainly for the western part of the city of Kyoto. The subjects were hospitalized and treated for AECOPD between October 2006 and July 2008. All subjects were evaluated and treated based on the clinical pathway for AECOPD. ${ }^{31}$ Therefore, the inclusion and exclusion criteria were identical to the clinical pathway for AECOPD that has been described elsewhere. ${ }^{31}$ Briefly, the inclusion criteria were: 1) a clinical diagnosis of COPD; 2) age over 40 years; 3 ) a history of smoking (10 pack-years or greater); 4) a forced expiratory volume in 1 second $\left(\mathrm{FEV}_{1}\right)$ / forced vital capacity (FVC) $<0.7$ on or before the first day of admission; 5) the absence of previous inflammatory changes on chest radiographs that influenced pulmonary function (for example, a previous thoracoplasty or tubercular sequelae); and 6) the presence of aggravated symptoms of COPD compatible with exacerbations. The exclusion criteria included intubation on the first day of admission, noninfective exacerbations including episodes due to pneumothorax or cardiac failure without AECOPD, and clinically relevant cardiac valvular disease.

Since it is believed that the therapeutic management of AECOPD with no clinical signs of pneumonia should be the same as for an exacerbation of COPD as a result of pneumonia, ${ }^{32}$ we included patients with COPD complicated by pneumonia. Most patients with a predominant clinical diagnosis of HF were admitted to the cardiac division, and thus they were not included in this present study.

In addition, 190 consecutive subjects with stable COPD were also recruited from the outpatient clinic of the Respiratory Division of the Kyoto-Katsura Hospital between September 2006 and August 2008. The entry criteria for stable COPD included: 1) a diagnosis of COPD; 2) age over 40 years; 3) a history of smoking; 4) a $\mathrm{FEV}_{1} / \mathrm{FVC}<0.7$; 5) regular attendance in the clinic for more than 6 months to avoid substantial changes brought about by new medical interventions; and 6) no changes in the treatment regimen for more than 4 weeks. Subjects with any history suggestive of asthma, an exacerbation of their COPD over the preceding 8 weeks, previous inflammatory changes revealed on chest radiographs that influenced pulmonary function (for example, 
a previous thoracoplasty or tubercular sequelae), or any other illness, were excluded. In addition, 43 patients were included in both the AECOPD group and in the stable phase.

\section{Measurements}

All AECOPD subjects who were hospitalized during this study period were evaluated and treated based on the clinical pathway for AECOPD. Regardless of whether the treatment was completed based on the clinical pathway or they later dropped out, the clinical pathway was used to evaluate the subjects immediately after seeing them. The details of this clinical pathway for AECOPD have been described elsewhere. ${ }^{31}$

Blood samples were obtained at the initial examination, and plasma BNP levels were measured by chemiluminescent enzyme immunoassay. Chest radiographs were obtained before admission in all subjects. Pulmonary function tests were performed after the inhalation of $200 \mu \mathrm{g}$ of salbutamol using a metered-dose inhaler with a spacer on the day after the completion of a 10-14 day oral course of glucocorticosteroids, or before discharge. According to the method described by the American Thoracic Society/European Respiratory Society Task Force in $2005,{ }^{33}$ three acceptable spirometric flow-volume curves were recorded with the patient sitting using a calibrated $2.0 \mathrm{~L}$ syringe before every measurement. The highest $\mathrm{FEV}_{1}$ and the highest $\mathrm{FVC}$ values among three maneuvers were then analyzed. The predicted values for the $\mathrm{FEV}_{1}$ and vital capacity were calculated according to the proposal from the Japan Society of Chest Diseases. ${ }^{34}$ The residual volume was measured by the closed-circuit helium method, and the diffusion capacity for carbon monoxide (DLco) was measured using the single-breath technique (CHESTAC-65V; Chest MI Inc., Tokyo, Japan). The outcome at 30 days after discharge from hospitalization with AECOPD was then analyzed. Successfully discharged subjects were defined as those who were alive without readmission at 30 days after discharge; unsuccessfully discharged subjects were defined as those who were readmitted within 30 days after discharge, died during hospitalization, or moved to another hospital for more intensive treatment.

As many patients with AECOPD as possible underwent transthoracic echocardiographic examinations on the first day of their admission. The echocardiographic recordings included Doppler analysis, and two-dimensional views that made it possible to determine the left ventricular ejection fraction (LVEF). Additional recordings enabling the assessment of diastolic functional indices using Doppler echocardiography (mitral flow and pulmonary venous flow) were performed where possible. From the mitral inflow profile, the E- and A-wave velocity and the deceleration time of the E wave (DTE) were measured, and the E/A velocity ratio was calculated. The flow velocities of the left or right upper pulmonary veins were recorded, and the ratio of the systolic to diastolic forward flow (S/D ratio) was calculated. Since the peak early diastolic velocity of the mitral annulus (Ea) was recorded, the ratio of the early transmitral velocity to the tissue Doppler mitral annular early diastolic velocity (E/Ea ratio) was also calculated. For this study, systolic dysfunction was defined as an ejection fraction of $<50 \%$. For diastolic dysfunction, impaired relaxation was defined as an E/A ratio $<0.8$, a DTE $>240 \mathrm{~ms}$ and when an isovolumic relaxation time (IVRT) measurement was available, an IVRT $>90$ $\mathrm{ms} .{ }^{27} \mathrm{~A}$ restrictive pattern was defined as an E/A ratio of 1.5 or more, a DTE $<160 \mathrm{~ms}$, and when an IVRT was available, an IVRT $<70 \mathrm{~ms}^{27}$

All eligible subjects with stable COPD underwent the following examinations on the same day: pulmonary function tests; arterial blood gas analysis; chest radiography; and measurements of plasma BNP levels. This measurement of plasma BNP levels was repeated every 6 months throughout the study period. The study was approved by the Ethics Committee of the Kyoto-Katsura Hospital.

\section{Statistical analysis}

All results are expressed as means \pm standard deviation, or medians (interquartile range) for BNP levels as their distributions were nonnormal, unless otherwise stated. Mann-Whitney $U$ tests were used to compare BNP levels between subjects first hospitalized with AECOPD and subjects with stable COPD, and between successfully and unsuccessfully discharged subjects. The significance of the intergroup differences based on the Global Initiative for Chronic Obstructive Lung Disease (GOLD) grades or study periods (before AECOPD, during AECOPD, and after AECOPD) was determined by an analysis of variance. When a significant difference was observed, Fisher's protected least significant difference method was used to identify where the differences occurred. The relationships between two sets of data were analyzed by Spearman's rank correlation tests. Unpaired Student's $t$-tests or chi-square tests were then used to compare values between groups. A $P$-value $<0.05$ was considered to be statistically significant.

\section{Results \\ Demographics}

During the study period, 87 hospitalizations in the 61 subjects were identified. In addition, 43 subjects were 
hospitalized only once due to AECOPD during the study period, and 12 subjects were hospitalized twice. Four subjects were hospitalized three times; two patients were hospitalized four times. Spirometry was performed in 81 out of 87 episodes before discharge or after completing oral corticosteroids for 10-14 days. The average age of the 61 subjects at their initial hospitalization was 75.4 years (Table 1). In 58 out of 61 subjects, the average postbronchodilator $\mathrm{FEV}_{1}$ was $1.07 \mathrm{~L}(56.0 \%$ predicted), and the $\mathrm{FEV}_{1} / \mathrm{FVC}$ was $45.2 \%$ (Table 1 ). In the other three subjects, spirometric results performed prior to admission were used. According to the grading of the severity of the airflow limitation in COPD described in the GOLD document, ${ }^{2}$ there were eleven (18.0\%), 22 (36.1\%), 20 (32.8\%), and eight (13.1\%) subjects, respectively, at grades I, II, III, and IV.

Table I Demographic details and outcomes for 61 subjects first hospitalized during the study period with acute exacerbations of chronic obstructive pulmonary disease

\begin{tabular}{|c|c|c|}
\hline & $\mathbf{N}$ & $\begin{array}{l}\text { Mean } \pm \text { SD } \\
\text { or } \mathbf{N}(\%)\end{array}$ \\
\hline Age (years) & 61 & $75.4 \pm 7.6$ \\
\hline Sex (male) & 61 & 49 (80.3\%) \\
\hline History of smoking (pack-years) & 61 & $76 \pm 41$ \\
\hline Body mass index $\left(\mathrm{kg} / \mathrm{m}^{2}\right)$ & 58 & $20.1 \pm 3.3$ \\
\hline Pneumonia as a complication (present) & 61 & $25(41.0 \%)$ \\
\hline \multicolumn{3}{|c|}{$\begin{array}{l}\text { Arterial blood gas at the beginning of the treatment with variable } \\
\text { concentration of oxygen }\end{array}$} \\
\hline $\mathrm{PaO}_{2}(\mathrm{mmHg})$ & 61 & $61.5 \pm 21.3$ \\
\hline $\mathrm{PaCO}_{2}(\mathrm{mmHg})$ & 61 & $46.4 \pm 18.5$ \\
\hline $\mathrm{pH}$ & 61 & $7.410 \pm 0.079$ \\
\hline B-type natriuretic peptide (pg/mL) & 61 & $126.8^{\mathrm{a}} \pm 177.5$ \\
\hline \multicolumn{3}{|l|}{ Management during the hospitalization } \\
\hline Oxygen administration & 61 & $51(83.6 \%)$ \\
\hline Noninvasive positive pressure ventilation & 61 & $23(37.7 \%)$ \\
\hline Mechanical ventilation with intubation & 61 & $\mathrm{I}(\mathrm{I} .6 \%)$ \\
\hline \multicolumn{3}{|l|}{ Pulmonary function tests after treatment } \\
\hline SVC (\% predicted) & 58 & $82.7 \pm 24.1$ \\
\hline FVC (\% predicted) & 58 & $81.0 \pm 22.8$ \\
\hline $\mathrm{FEV}_{1}(\%$ predicted $)$ & 58 & $56.0 \pm 23.8$ \\
\hline $\mathrm{FEV}_{\mathrm{I}} / \mathrm{FVC}(\%)$ & 58 & $45.2 \pm 14.4$ \\
\hline TLC (\% predicted) & 55 & $102.0 \pm 20.6$ \\
\hline $\mathrm{DL}_{\mathrm{co}}(\mathrm{mL} / \mathrm{min} / \mathrm{mmHg})$ & 47 & $6.79 \pm 3.83$ \\
\hline $\mathrm{DL}_{\mathrm{CO}}(\%$ predicted $)$ & 47 & $48.8 \pm 22.0$ \\
\hline $\mathrm{DL}_{\mathrm{co}} / \mathrm{V}_{\mathrm{A}}(\mathrm{mL} / \mathrm{min} / \mathrm{mmHg} / \mathrm{L})$ & 47 & $1.86 \pm 1.06$ \\
\hline Length of stay (days) & 82 & $21.5 \pm 24.6$ \\
\hline Readmission within 30 days, number (\%) & 54 & $6(11.1 \%)$ \\
\hline Mortality within hospitalization, number (\%) & 59 & $2(3.4 \%)$ \\
\hline Mortality within 30 days, number (\%) & 59 & $2(3.4 \%)$ \\
\hline Mortality within 90 days, number (\%) & 58 & $3(5.2 \%)$ \\
\hline
\end{tabular}

Note: aMedian (interquartile range) 55.4 (26.9-129.3).

Abbreviations: $\mathrm{SD}$, standard deviation; $\mathrm{PaO}_{2}$, partial pressure of oxygen in arterial blood; $\mathrm{PaCO}_{2}$, partial pressure of carbon dioxide in arterial blood; SVC, slow vital capacity; FVC, forced vital capacity; FEV , forced expiratory volume in I second; TLC, total lung capacity; $\mathrm{DL}_{\mathrm{co}}$, diffusion capacity for carbon monoxide; $\mathrm{DL}_{\mathrm{CO}} / \mathrm{V}_{\mathrm{A}}$, diffusion capacity for carbon monoxide/alveolar volume.
In 25 patients $(41.0 \%)$, chest radiographs revealed infiltration compatible with pneumonia.

\section{Plasma BNP levels}

The median plasma BNP level was 55.4 (26.9-129.3) pg/mL at the first hospitalization with AECOPD during the study period, and in the stable patients, it was $21.5(10.3-47.5) \mathrm{pg} / \mathrm{mL}$ (Table 2). This difference was statistically significant at $P<0.0001$. On the other hand, for stable COPD, median plasma BNP levels did not differ significantly $(P=0.53)$ across GOLD grades: 18.3 (10.0-45.3) for GOLD grade I, 25.8 (11.0-53.7) for grade II, 22.1 (9.1-52.6) for grade III, and 17.2 (9.6-22.9) pg/mL for grade IV (Figure 1).

Since the measurement of plasma BNP levels was performed every 6 months, the plasma BNP levels had been measured within 1 month before admission in 15 subjects (Figure 2), in whom the plasma BNP levels changed significantly $(P=0.002)$. Before admission, the plasma BNP level was 19.4 (9.8-32.2) $\mathrm{pg} / \mathrm{mL}$, and rose to 72.7 (27.7-146.3) $\mathrm{pg} / \mathrm{mL}$ during AECOPD $(P=0.0033)$, and then fell over a month from exacerbation to 14.6 (12.9-39.0) $\mathrm{pg} / \mathrm{mL}$ $(P=0.0013)$. The pre- and post-values were not statistically different $(P=0.75)$.

Following the first hospitalization with AECOPD, there were 48 successfully discharged subjects

Table 2 Demographic details of 190 subjects with stable chronic obstructive pulmonary disease

\begin{tabular}{|c|c|c|c|c|}
\hline & Mean & SD & Maximum & Minimum \\
\hline Age (years) & 71.7 & 8.7 & 96.0 & 40.0 \\
\hline BMI $\left(\mathrm{kg} / \mathrm{m}^{2}\right)$ & 21.9 & 3.2 & 31.6 & 13.9 \\
\hline $\begin{array}{l}\text { Cumulative smoking } \\
\text { (pack-years) }\end{array}$ & 71 & 42 & 268 & 4 \\
\hline SVC (\% predicted) & 99.8 & 22.8 & 154.0 & 42.6 \\
\hline FVC (\% predicted) & 95.6 & 23.1 & 148.5 & 40.0 \\
\hline $\mathrm{FEV}_{1}$ (\% predicted) & 66.6 & 27.4 & 133.0 & 13.0 \\
\hline $\mathrm{FEV}_{1} / \mathrm{FVC}(\%)$ & 47.5 & 13.5 & 69.9 & 21.4 \\
\hline TLC (\% predicted) & 108.5 & 16.8 & 160.6 & 68.8 \\
\hline $\mathrm{DL}_{\mathrm{co}}^{\mathrm{a}}(\%$ predicted $)$ & 62.4 & 28.7 & 174.7 & 2.5 \\
\hline $\mathrm{PaO}_{2}^{\mathrm{b}}(\mathrm{mmHg})$ & 78.5 & 11.7 & 105.5 & 49.2 \\
\hline $\mathrm{PaCO}_{2}^{\mathrm{b}}(\mathrm{mmHg})$ & 39.8 & 5.3 & 57.7 & 29.3 \\
\hline $\mathrm{pH}$ (arterial blood) ${ }^{\mathrm{b}}$ & 7.433 & 0.027 & 7.511 & 7.337 \\
\hline $\mathrm{BNP}(\mathrm{pg} / \mathrm{mL})$ & $51.8^{\mathrm{c}}$ & 111.5 & $\mathrm{I}, 180.0$ & 3.9 \\
\hline Sex & \multicolumn{4}{|c|}{166 male/24 female } \\
\hline Smoking history & \multicolumn{4}{|c|}{32 current/ 158 former } \\
\hline
\end{tabular}

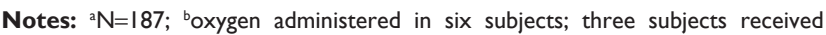
noninvasive positive pressure ventilation at home; 'median (interquartile range) 21.5 (10.3-47.5).

Abbreviations: SD, standard deviation; BMI, body mass index; SVC, slow vital capacity; FVC, forced vital capacity; $\mathrm{FEV}_{1}$, forced expiratory volume in I second; TLC, total lung capacity; $\mathrm{DL}_{\mathrm{co}}$, diffusion capacity for carbon monoxide; $\mathrm{PaO}_{2}$, partial pressure of oxygen in arterial blood; $\mathrm{PaCO}_{2}$, partial pressure of carbon dioxide in arterial blood; BNP, B-type natriuretic peptide; $\mathrm{pH}$, power of hydrogen. 


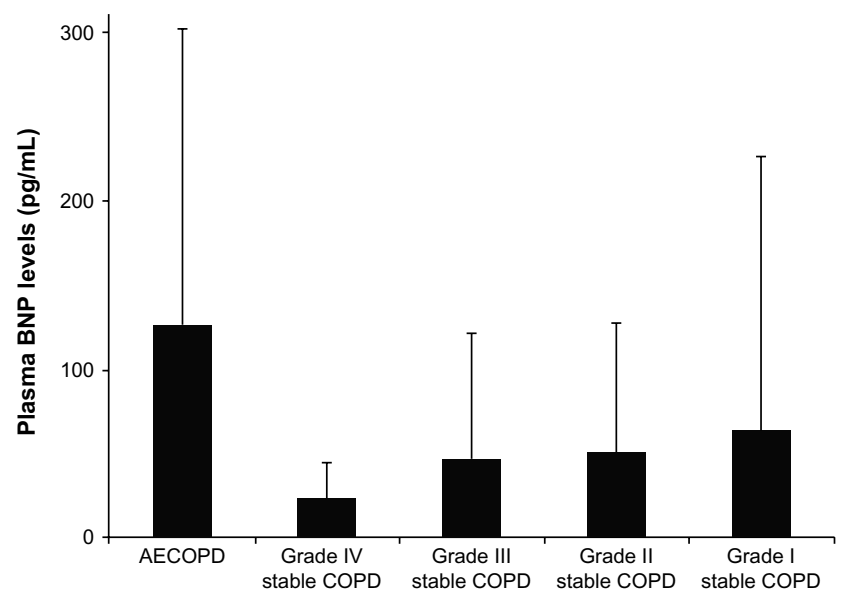

Figure I Cross-sectional comparisons of plasma BNP levels (means \pm standard deviation) in 61 subjects first hospitalized with AECOPD, in 65 subjects at GOLD grade I with stable COPD, in 65 subjects at grade II, in 40 subjects at grade III, and in 20 subjects at grade IV.

Notes: Plasma BNP levels were not statistically different among the GOLD grades $(P=0.53)$, but the plasma BNP levels measured in $6 \mathrm{I}$ subjects first hospitalized with AECOPD were statistically higher than in subjects with stable COPD at each GOLD grade $(P<0.00$ I)

Abbreviations: AECOPD, acute exacerbations of chronic obstructive pulmonary disease; COPD, chronic obstructive pulmonary disease; BNP, B-type natriuretic peptide; GOLD, Global Initiative for Chronic Obstructive Lung Disease.

(hospitalization length, 19 \pm 20 days). There were ten unsuccessfully discharged subjects, including six who were readmitted within 30 days after discharge, two who died during hospitalization, and two who moved to another hospital for more intensive care. Three patients could not be followed after discharge and were excluded from the analysis. Median plasma BNP levels during AECOPD were significantly higher in the ten unsuccessfully discharged subjects $(260.5[59.4-555.0] \mathrm{pg} / \mathrm{mL})$ than in those discharged successfully, (48.5 [24.2-104.0] pg/mL, $P=0.0066)$.

\section{Echocardiography}

Transthoracic echocardiograms were examined in 54 patients. The average value for the LVEF was $69 \%$ and was under 50\% in three episodes (5.6\%) (Table 3 ). In terms of diastolic function, the E/A velocity ratio was determined in 38 subjects and was found to be $<0.8(63.2 \%)$. The DTE was $>240 \mathrm{~ms}$ in six (13.0\%) out of the 46 patients studied. The S/D ratio was below 1.0 in four $(28.6 \%)$ out of 14 patients in whom this measurement could be collected. The E/Ea ratio was 15.0 or more in four $(9.3 \%)$ out of 43 subjects without systolic dysfunction. Using those criteria, only four subjects $(7.4 \%)$ were considered to show impaired relaxation. A restrictive pattern of left ventricular (LV) function was never observed. The Spearman's rank correlation coefficients $(R s)$ between the plasma BNP levels and the systolic and diastolic functional indices are also listed in Table 3. BNP levels were weakly correlated with the $\mathrm{E} / \mathrm{Ea}$ ratio $(R s=0.353$, $P=0.018$ ), but they were not correlated with the LVEF (Rs $=-0.221, P=0.108)$.

\section{Discussion}

This report confirms previous observations that plasma BNP levels are slightly but significantly elevated during AECOPD in most subjects with COPD, although the BNP levels varied quite widely between subjects with stable COPD, and that BNP rises during an exacerbation, and then returns

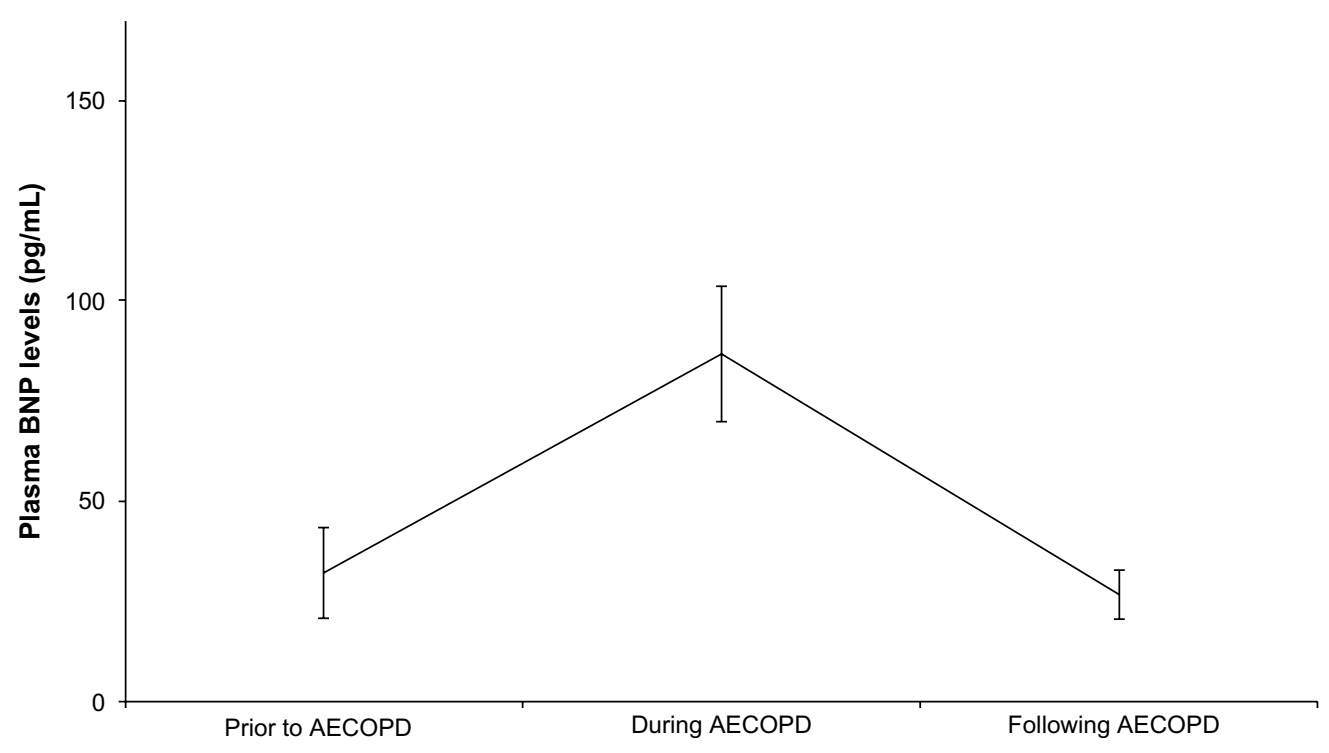

Figure 2 Longitudinal comparisons of plasma BNP levels in 15 subjects before AECOPD, during AECOPD and after AECOPD.

Note: Bars indicate standard errors.

Abbreviations: AECOPD, acute exacerbations of chronic obstructive pulmonary disease; BNP, B-type natriuretic peptide. 
Table 3 Transthoracic echocardiographic findings and correlation with plasma BNP levels in 6I subjects with acute exacerbation of COPD

\begin{tabular}{|c|c|c|c|c|c|c|c|c|}
\hline & \multirow[t]{2}{*}{ Number } & \multirow[t]{2}{*}{ Mean } & \multirow[t]{2}{*}{ Median } & \multirow[t]{2}{*}{ SD } & \multirow[t]{2}{*}{ Maximum } & \multirow[t]{2}{*}{ Minimum } & \multicolumn{2}{|c|}{$\begin{array}{l}\text { Correlation } \\
\text { with BNP }\end{array}$} \\
\hline & & & & & & & Rs & $P$-value \\
\hline LAD (mm) & 53 & 31 & 29 & 10 & 83 & 19 & 0.054 & 0.696 \\
\hline IVST (mm) & 54 & 9 & 9 & 1 & 12 & 6 & -0.023 & 0.868 \\
\hline LVPWth (mm) & 54 & 9 & 9 & 1 & 12 & 6 & -0.003 & 0.981 \\
\hline LVDd (mm) & 54 & 44 & 44 & 6 & 60 & 31 & 0.332 & 0.016 \\
\hline LVDs (mm) & 54 & 27 & 27 & 6 & 47 & 18 & 0.283 & 0.039 \\
\hline $\mathrm{EDV}(\mathrm{mL})$ & 54 & 91 & 87 & 29 & 182 & 37 & 0.331 & 0.016 \\
\hline ESV $(m L)$ & 53 & 29 & 26 & 17 & 104 & 9 & 0.284 & 0.041 \\
\hline $\mathrm{EF}(\%)$ & 54 & 69 & 71 & 10 & 83 & 32 & -0.221 & 0.108 \\
\hline FS (\%) & 54 & 39 & 40 & 7 & 52 & 14 & -0.141 & 0.303 \\
\hline $\mathrm{SV}(\mathrm{mL})$ & 54 & 61 & 62 & 18 & 103 & 25 & 0.244 & 0.075 \\
\hline $\mathrm{CO}(\mathrm{L} / \mathrm{min})$ & 46 & 5.25 & 5.12 & 1.37 & 8.60 & 2.80 & 0.038 & 0.797 \\
\hline E-wave velocity (m/sec) & 50 & 0.67 & 0.63 & 0.32 & 1.67 & 0.29 & 0.299 & 0.036 \\
\hline A-wave velocity $(\mathrm{m} / \mathrm{sec})$ & 43 & 0.82 & 0.80 & 0.24 & 1.30 & 0.34 & -0.072 & 0.641 \\
\hline E/A ratio & 41 & 0.74 & 0.74 & 0.23 & 1.23 & 0.35 & 0.156 & 0.325 \\
\hline Deceleration time of the E wave (DTE) (msec) & 48 & 181 & 180 & 72 & 383 & 58 & -0.205 & 0.160 \\
\hline$S / D$ ratio & 16 & 1.25 & 1.29 & 0.34 & 1.83 & 0.79 & -0.278 & $0.28 \mathrm{I}$ \\
\hline Ea velocity $(\mathrm{m} / \mathrm{sec})$ & 47 & 0.09 & 0.07 & 0.15 & 1.10 & 0.03 & -0.172 & 0.243 \\
\hline E/Ea ratio & 46 & 10.47 & 9.40 & 5.80 & 32.75 & 3.91 & 0.353 & 0.018 \\
\hline
\end{tabular}

Note: Rs, Spearman's rank correlation coefficients.

Abbreviations: COPD, chronic obstructive pulmonary disease; SD, standard deviation; BNP, B-type natriuretic peptide; LAD, left atrial dimension; IVST, interventricular septum thickness; LVPWth, left ventricular posterior wall thickness; LVDd, left ventricular end-diastolic dimension; LVDs, left ventricular internal dimension in systole; EDV, end-diastolic volume; ESV, end-systolic volume; EF, ejection fraction; FS, fractional shortening; SV, stroke volume; CO, cardiac output; S/D ratio, ratio of systolic to diastolic forward flow; Ea, peak early diastolic velocity of the mitral annulus.

to the baseline level on recovery. ${ }^{28,35}$ This demonstrates that the elevated BNP levels are related in some way to the exacerbation. Despite this elevation of BNP, we showed that cardiac systolic and diastolic dysfunction was present in only a small number of episodes with AECOPD.

It has been reported since the 1990s that the prevalence of COPD ranges from $10 \%-32 \%$ in patients with chronic heart failure. ${ }^{7-11}$ Coexisting LV dysfunction was observed in $32 \%$ of patients with COPD presenting with symptomatic deterioration. ${ }^{6}$ Rutten et al reported that approximately $30 \%$ of patients with stable COPD have some degree of $\mathrm{HF}^{20}$ However, after the concept of diastolic dysfunction became widely appreciated, it was then reported that heart failure was mainly due to diastolic dysfunction, especially in subjects with COPD ${ }^{36,37}$ Abroug et al examined 148 patients admitted to the intensive care unit for AECOPD and found systolic dysfunction in $11.5 \%$, diastolic dysfunction in $32.4 \%$, and both in $6.8 \%$ of the patients using the same criteria of systolic and diastolic dysfunction employed in the present study. ${ }^{27}$ Abusaid et al also reported that diastolic dysfunction was observed in $60.4 \%$ of 139 patients hospitalized for AECOPD, although they did not provide specific criteria for the diagnosis. ${ }^{29}$

As compared with previous reports, the prevalence of LV failure was low in our study. There is no doubt that the prevalence of diastolic dysfunction will be determined by the definition of diastolic dysfunction that was used. In the present study, using the sole criterion of an E/A ratio $<1.0$, diastolic dysfunction would be found in $90 \%$ of cases. However, we reanalyzed our data using the same criteria for diastolic dysfunction as Abroug. ${ }^{27}$ Despite this, the prevalence of diastolic dysfunction was still very different from the Abroug report. One possible reason may be that the patients included in Abroug's study had more severe AECOPD, since they had been admitted to an intensive care unit, presumably because of respiratory failure.

It has been reported that the elevated levels of NT-proBNP are one of the mortality predictors among patients admitted to the hospital with AECOPD, although the pathophysiological basis for this is unknown. ${ }^{38-40}$ The present study also confirmed that the plasma BNP levels during AECOPD may be an important determinant of successful discharge.

In our study, although AECOPD appeared to have had little impact on cardiac function, plasma BNP levels were elevated. There are at least two possible mechanisms for this rise. First, pulmonary hyperinflation has the potential for significant adverse effects on cardiovascular function in COPD ${ }^{41}$ and AECOPD is characterized by worsening lung hyperinflation. ${ }^{42}$ It is possible that BNP was released from the 
heart as a result of this, rather than as a direct effect of intrinsic myocardial function. Second, BNP may reflect systemic or lung inflammation during AECOPD that is qualitatively or quantitatively different from stable COPD. ${ }^{43}$ This modification of inflammation may be related to LV preload through systemic vasoconstriction, or alternatively lung hyperinflation or inflammation may be causing the increase in BNP levels via an increase in left ventricular wall stress.

This single-center study was limited by the number of patients with AECOPD admitted to the study site and does include all the patients with AECOPD and stable COPD seen in this hospital during the 22-month study period. Some measurements were not completed during echocardiography since it was difficult to obtain all of the echocardiographic measurements, especially in patients with COPD because of their hyperinflation. The fact that the E/A ratio was obtained in only 41 out of 54 patients might have introduced some bias in the proportion of patients with a final diagnosis of diastolic dysfunction. Unfortunately, we do not have a record of whether the patients were in atrial fibrillation at the time of presentation, or had reduced creatinine clearance, both of which are known to raise BNP levels. Patients with stable COPD did not undergo transthoracic echocardiographic examinations, but we do not see this to be a major limitation, since the focus of our interest was on AECOPD, not the stable state.

\section{Conclusion}

Plasma BNP levels were slightly but significantly elevated during AECOPD in most subjects with COPD, although a wide range of BNP levels were seen in subjects with stable COPD. Echocardiographic examinations indicated cardiac systolic and diastolic dysfunction in only a small number of patients during the AECOPD.

\section{Author contributions}

$\mathrm{KN}$ was the physician responsible for all participants, planned the study design, and prepared the manuscript. TN participated in the data collection and the care for the participants. KO was a scientific adviser for cardiology. TO performed the statistical analysis. YH and PWJ contributed to the data analysis and the interpretation and editing of the manuscript. All the authors contributed toward data analysis, drafting and revising the manuscript.

\section{Acknowledgments}

The study was performed at the Kyoto-Katsura Hospital, Kyoto, Japan. This study was partly funded by the NPO
Medise in Japan. This manuscript was first written while KN was an academic visitor at the Division of Clinical Science, St George's Hospital Medical School, London, England.

\section{Disclosure}

The authors report no conflicts of interest in this work.

\section{References}

1. Price LC, Lowe D, Hosker HS, Anstey K, Pearson MG, Roberts CM; British Thoracic Society and the Royal College of Physicians Clinical Effectiveness Evaluation Unit (CEEu). UK National COPD Audit 2003: Impact of hospital resources and organisation of care on patient outcome following admission for acute COPD exacerbation. Thorax. 2006;61(10):837-842.

2. Vestbo J, Hurd SS, Agustí AG, et al. Global strategy for the diagnosis, management, and prevention of chronic obstructive pulmonary disease: GOLD executive summary. Am J Respir Crit Care Med. 2013;187(4):347-365.

3. Wakabayashi K, Gonzalez MA, Delhaye C, et al. Impact of chronic obstructive pulmonary disease on acute-phase outcome of myocardial infarction. Am J Cardiol. 2010;106(3):305-309.

4. Donaldson GC, Hurst JR, Smith CJ, Hubbard RB, Wedzicha JA Increased risk of myocardial infarction and stroke following exacerbation of COPD. Chest. 2010;137(5):1091-1097.

5. Brekke PH, Omland T, Smith P, Søyseth V. Underdiagnosis of myocardial infarction in COPD - Cardiac Infarction Injury Score (CIIS) in patients hospitalised for COPD exacerbation. Respir Med. 2008;102(9): 1243-1247.

6. Render ML, Weinstein AS, Blaustein AS. Left ventricular dysfunction in deteriorating patients with chronic obstructive pulmonary disease. Chest. 1995;107(1):162-168.

7. Ni H, Nauman DJ, Hershberger RE. Managed care and outcomes of hospitalization among elderly patients with congestive heart failure. Arch Intern Med. 1998;158(11):1231-1236.

8. Havranek EP, Masoudi FA, Westfall KA, Wolfe P, Ordin DL, Krumholz HM. Spectrum of heart failure in older patients: results from the National Heart Failure project. Am Heart J. 2002;143(3):412-417.

9. Braunstein JB, Anderson GF, Gerstenblith G, et al. Noncardiac comorbidity increases preventable hospitalizations and mortality among Medicare beneficiaries with chronic heart failure. $J \mathrm{Am}$ Coll Cardiol. 2003;42(7):1226-1233.

10. Gustafsson F, Torp-Pedersen C, Burchardt H, et al; DIAMOND Study Group. Female sex is associated with a better long-term survival in patients hospitalized with congestive heart failure. Eur Heart $J$. 2004;25(2):129-135.

11. Holguin F, Folch E, Redd SC, Mannino DM. Comorbidity and mortality in COPD-related hospitalizations in the United States, 1979 to 2001 Chest. 2005;128(4):2005-2011.

12. Rutten FH, Cramer MJ, Grobbee DE, et al. Unrecognized heart failure in elderly patients with stable chronic obstructive pulmonary disease. Eur Heart J. 2005;26(18):1887-1894.

13. Curkendall SM, DeLuise C, Jones JK, et al. Cardiovascular disease in patients with chronic obstructive pulmonary disease, Saskatchewan Canada cardiovascular disease in COPD patients. Ann Epidemiol. 2006; 16(1):63-70.

14. Le Jemtel TH, Padeletti M, Jelic S. Diagnostic and therapeutic challenges in patients with coexistent chronic obstructive pulmonary disease and chronic heart failure. J Am Coll Cardiol. 2007;49(2):171-180.

15. Iversen KK, Kjaergaard J, Akkan D; ECHOS-Lung Function Study Group. Chronic obstructive pulmonary disease in patients admitted with heart failure. J Intern Med. 2008;264(4):361-369.

16. Padeletti M, Jelic S, LeJemtel TH. Coexistent chronic obstructive pulmonary disease and heart failure in the elderly. Int $J$ Cardiol. 2008;125(2):209-215. 
17. Barr RG, Bluemke DA, Ahmed FS, et al. Percent emphysema, airflow obstruction, and impaired left ventricular filling. $N$ Engl J Med. 2010;362(3):217-227.

18. Cowie MR, Struthers AD, Wood DA, et al. Value of natriuretic peptides in assessment of patients with possible new heart failure in primary care. Lancet. 1997;350(9088):1349-1353.

19. Maisel AS, Krishnaswamy P, Nowak RM, et al; Breathing Not Properly Multinational Study Investigators. Rapid measurement of B-type natriuretic peptide in the emergency diagnosis of heart failure. $N$ Engl J Med. 2002;347(3):161-167.

20. Rutten FH, Moons KG, Cramer MJ, et al. Recognising heart failure in elderly patients with stable chronic obstructive pulmonary disease in primary care: cross sectional diagnostic study. BMJ. 2005; 331(7529):1379.

21. Morrison LK, Harrison A, Krishnaswamy P, Kazanegra R, Clopton P, Maisel A. Utility of a rapid B-natriuretic peptide assay in differentiating congestive heart failure from lung disease in patients presenting with dyspnea. J Am Coll Cardiol. 2002;39(2):202-209.

22. Green SM, Martinez-Rumayor A, Gregory SA, et al. Clinical uncertainty, diagnostic accuracy, and outcomes in emergency department patients presenting with dyspnea. Arch Intern Med. 2008;168(7):741-748.

23. Januzzi JL Jr, Camargo CA, Anwaruddin S, et al. The N-terminal Pro-BNP investigation of dyspnea in the emergency department (PRIDE) study. Am J Cardiol. 2005;95(8):948-954.

24. Pesola GR. The use of B-type natriuretic peptide (BNP) to distinguish heart failure from lung disease in patients presenting with dyspnea to the emergency department. Acad Emerg Med. 2003;10(3): 275-277.

25. Dickstein K, Cohen-Solal A, Filippatos G, et al; ESC Committee for Practice Guidelines (CPG). ESC Guidelines for the diagnosis and treatment of acute and chronic heart failure 2008: the Task Force for the Diagnosis and Treatment of Acute and Chronic Heart Failure 2008 of the European Society of Cardiology. Developed in collaboration with the Heart Failure Association of the ESC (HFA) and endorsed by the European Society of Intensive Care Medicine (ESICM). Eur Heart J. 2008;29(19):2388-2442.

26. Bozkanat E, Tozkoparan E, Baysan O, Deniz O, Ciftci F, Yokusoglu M. The significance of elevated brain natriuretic peptide levels in chronic obstructive pulmonary disease. J Int Med Res. 2005;33(5): 537-544.

27. Abroug F, Ouanes-Besbes L, Nciri N, et al. Association of left-heart dysfunction with severe exacerbation of chronic obstructive pulmonary disease: diagnostic performance of cardiac biomarkers. Am J Respir Crit Care Med. 2006;174(9):990-996.

28. Inoue Y, Kawayama T, Iwanaga T, Aizawa H. High plasma brain natriuretic peptide levels in stable COPD without pulmonary hypertension or cor pulmonale. Intern Med. 2009;48(7):503-512.
29. Abusaid GH, Barbagelata A, Tuero E, Mahmood A, Sharma G. Diastolic dysfunction and COPD exacerbation. Postgrad Med. 2009;121(4):76-81.

30. Iwanaga Y, Nishi I, Furuichi S, et al. B-type natriuretic peptide strongly reflects diastolic wall stress in patients with chronic heart failure: comparison between systolic and diastolic heart failure. J Am Coll Cardiol. 2006;47(4):742-748.

31. Nishimura K, Yasui M, Nishimura T, Oga T. Clinical pathway for acute exacerbations of chronic obstructive pulmonary disease: method development and five years of experience. Int J Chron Obstruct Pulmon Dis. 2011;6:365-372.

32. Lieberman D, Lieberman D, Gelfer Y, et al. Pneumonic vs nonpneumonic acute exacerbations of COPD. Chest. 2002;122(4):1264-1270.

33. Miller MR, Hankinson J, Brusasco V, et al; ATS/ERS Task Force. Standardisation of spirometry. Eur Respir J. 2005;26(2):319-338.

34. Japan Society of Chest Diseases: The predicted values of pulmonary function testing and arterial blood gas in Japanese. Jpn J Thorac Dis. 2001;39(5):appendix. Japanese.

35. Stolz D, Breidthardt T, Christ-Crain M, et al. Use of B-type natriuretic peptide in the risk stratification of acute exacerbations of COPD. Chest. 2008;133(5):1088-1094.

36. Aurigemma GP, Gaasch WH. Clinical practice. Diastolic heart failure. N Engl J Med. 2004;351(11):1097-1105.

37. Vasan RS, Levy D. Defining diastolic heart failure: a call for standardized diagnostic criteria. Circulation. 2000;101(17):2118-2121.

38. Chang CL, Robinson SC, Mills GD, et al. Biochemical markers of cardiac dysfunction predict mortality in acute exacerbations of COPD. Thorax. 2011;66(9):764-768.

39. Gale CP, White JE, Hunter A, et al. Predicting mortality and hospital admission in patients with COPD: significance of NT pro-BNP, clinical and echocardiographic assessment. J Cardiovasc Med (Hagerstown). 2011;12(9):613-618.

40. Høiseth AD, Omland T, Hagve TA, Brekke PH, Søyseth V. NT-proBNP independently predicts long term mortality after acute exacerbation of COPD - a prospective cohort study. Respir Res. 2012;13:97.

41. Tzani P, Aiello M, Elia D, et al. Dynamic hyperinflation is associated with a poor cardiovascular response to exercise in COPD patients. Respir Res. 2011;12:150.

42. Parker CM, Voduc N, Aaron SD, Webb KA, O’Donnell DE. Physiological changes during symptom recovery from moderate exacerbations of COPD. Eur Respir J. 2005;26(3):420-428.

43. Fujimoto K, Yasuo M, Urushibata K, Hanaoka M, Koizumi T, Kubo K. Airway inflammation during stable and acutely exacerbated chronic obstructive pulmonary disease. Eur Respir J. 2005;25(4):640-646.
International Journal of COPD

\section{Publish your work in this journal}

The International Journal of COPD is an international, peer-reviewed journal of therapeutics and pharmacology focusing on concise rapid reporting of clinical studies and reviews in COPD. Special focus is given to the pathophysiological processes underlying the disease, intervention programs, patient focused education, and self management protocols.

\section{Dovepress}

This journal is indexed on PubMed Central, MedLine and CAS. The manuscript management system is completely online and includes a very quick and fair peer-review system, which is all easy to use. Visit $\mathrm{http}: / /$ www.dovepress.com/testimonials.php to read real quotes from published authors. 